Cita bibliográfica: Miró Pérez, J. J. y Olcina Cantos, J. (2020). Cambio climático y confort térmico. Efectos en el turismo de la Comunidad Valenciana. Investigaciones Turísticas (20), pp. 1-30. https://doi.org/10.14198/ INTURI2020.20.01

\title{
Cambio climático y confort térmico. Efectos en el turismo de la Comunidad Valenciana
}

\section{Climatic change and thermal comfort. Effects on the tourism industry in the region of Valencia}

\author{
Juan Javier Miró Pérez (iD, Universitat de València, España \\ jamipe@uv.es
}

Jorge Olcina Cantos iD, Universidad de Alicante, España Jorge.Olcina@ua.es

\section{RESUMEN}

El cambio climático comienza a manifestar efectos en las actividades económicas de la Comunidad Valenciana. El turismo es una parte fundamental de su economía, puesto que representa el $15 \%$ de su PIB regional. La modalidad de "sol y playa" es la principal actividad turística en el territorio valenciano, de ahí la importancia del análisis de las alteraciones que están experimentando los elementos climáticos debido a su efecto en el recurso turístico y en las preferencias de la demanda. La pérdida del "confort climático", el aumento de las noches "tropicales" ( $\mathrm{T} \underline{\mathrm{a}}>2 \mathbf{2 0}^{\circ} \mathrm{C}$ ), el incremento de la temperatura del agua de mar Mediterráneo y la adaptación a los extremos atmosféricos (olas de calor, lluvias intensas, sequías) son los principales desafíos en las políticas de adaptación al cambio climático en el turismo valenciano

Palabras clave: cambio climático; confort térmico; turismo; Comunidad Valenciana; medidas de adaptación.

\section{ABSTRACT}

Climate change is beginning to have an impact on the economic activities of the Region of Valencia. Tourism is a fundamental activity of this region's economy, representing $15 \%$ of its GDP. The "sun and beach" tourism product constitutes the main tourist activity in the region, hence the importance of analyzing the changes occurring in climatic elements because of their effects on tourism resources and demand preferences. The loss of "climatic comfort", the increase of "tropical" nights (T으 $>20$ ), the rise in seawater temperatures and the adaptation to atmospheric extremes (heat waves, intense rains, droughts) are the main challenges faced by Valencia's tourism industry when designing policies to adapt to climate change. 
Keywords: climate change; thermal comfort; tourism; Valencian region (Spain); adaptation measures.

\section{INTRODUCCIÓN: CAMBIO CLIMÁTICO Y TURISMO EN LA COMUNIDAD VALENCIANA. PRINCIPALES EFECTOS}

El turismo es la actividad económica más expuesta a los efectos del calentamiento global. Es cierto que la agricultura ocupa mayor extensión territorial y es, asimismo, una actividad muy expuesta al cambio climático, pero el turismo tiene un impacto socio-económico mucho mayor en un mundo cada vez más globalizado y urbano (Stern, 2006; Bigano et al., 2008). La actividad turística, con todas sus modalidades, mueve a más de mil millones (1.400 en 2018) de turistas al año en todo el mundo, supone unos ingresos totales de 1,7 billones de dólares (UNWTO, 2019) y representa el 10\% del PIB mundial. En España ese porcentaje alcanza el 14,6\% del PIB, con unos ingresos de 178 mil millones de $€$ en 2018 (WTTC, 2019; INE, 2019).

La actividad turística es posible por la existencia de unos recursos que se dan en el territorio y que explican el desplazamiento del ser humano en la búsqueda de experiencias, evasión o placer con su disfrute. El turismo es, sin duda, la forma más desarrollada y conseguida de escapismo (Tuan, 2018). Y, en su razón de ser, las condiciones físicas del medio donde se desarrolla tienen un papel principal. La dimensión espacial del turismo es el fundamento de su naturaleza geográfica (López Palomeque et al., 2011). En el contexto actual de cambios acelerados, de globalización bajo los principios de un capitalismo feroz, cualquier alteración en los elementos del medio físico puede afectar de modo considerable a la actividad económica de un territorio (Sauri et al., 2011). El mantenimiento de los recursos territoriales que favorecen la actividad turística en los principales destinos mundiales se presenta, en la actualidad, como proceso plagado de incertidumbres debido a las modificaciones que comienzan a experimentar de forma evidente las condiciones climáticas terrestres (Beck, 2002; Olcina et al., 2019).

Los recursos naturales, principal atractivo para la generación de productos turísticos, están siendo -y lo serán más en las próximas décadas- afectados por el calentamiento climático de causa antrópica (IPCC, 2014, 2018). De forma que, de constituir bases sólidas y estables para el desarrollo turístico de los territorios, se convierten en agentes de cambio de destinos y modalidades turísticas, al tener éstos que adaptarse a la nueva realidad climática y ambiental (Figura 1). Pero, además, la actividad turística es un agente de cambio climático, al emitir gases de efecto invernadero que contribuyen a aumentar el proceso de calentamiento, especialmente por los procesos de desplazamiento y los medios de transporte necesarios para el acceso a los destinos (Amelung et al., 2007; Gössling et al., 2008; Scott, 2008; Scott et al., 2011; Lenzen et al., 2018). 
Figura 1. Cambios en el recurso clima causado por el calentamiento global en destinos turísticos
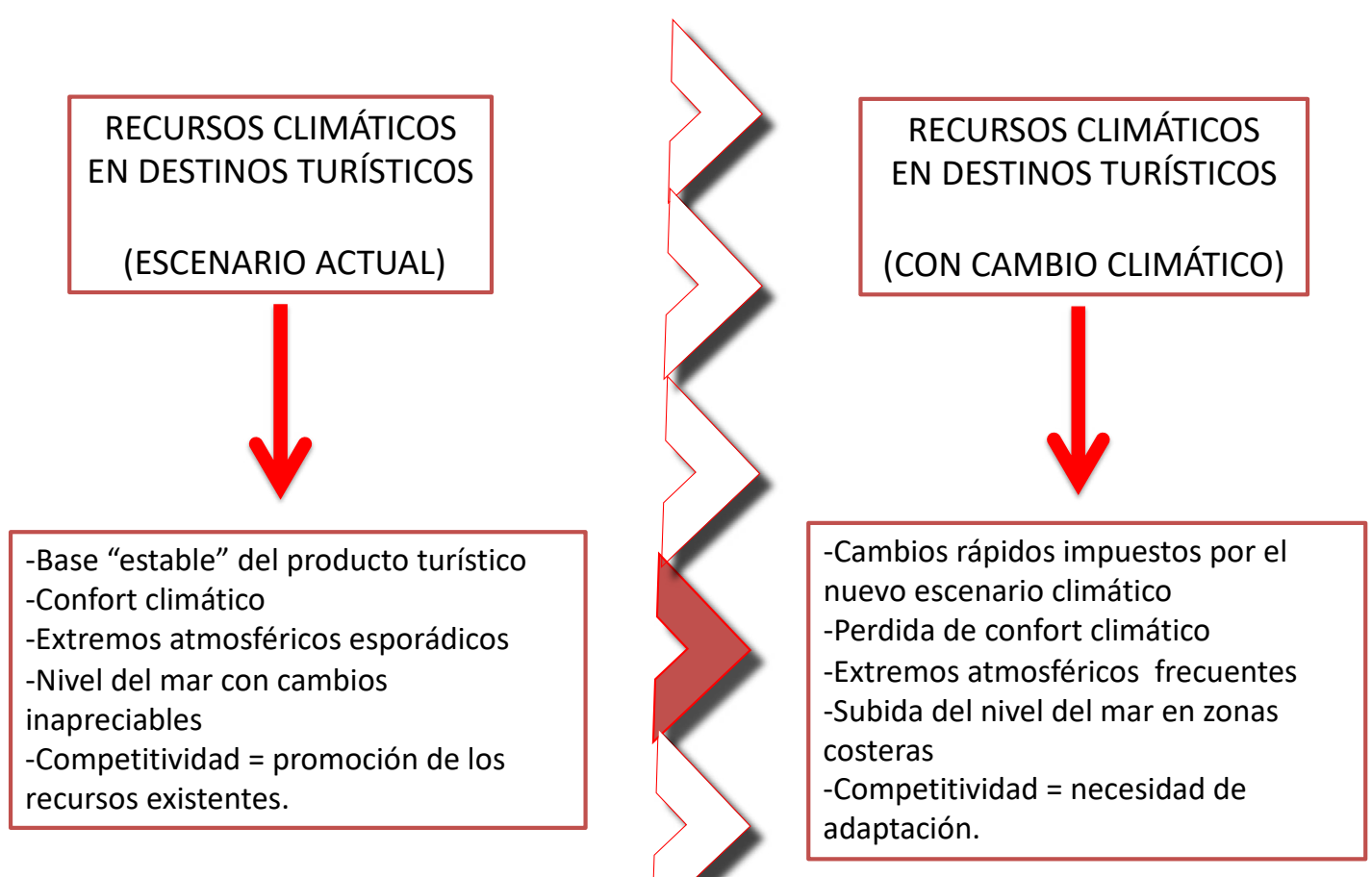

Elaboración propia.

Cambio climático y turismo interactúan en el marco del actual escenario de calentamiento térmico planetario. Son dos procesos que se retroalimentan, puesto que ambos son a la vez causa y consecuencia del mismo. La actividad turística es fuente de emisiones y por tanto responsable de la modificación que se está experimentando en el balance energético planetario por forzamiento radiativo de causa antrópica. Y, a su vez, el cambio previsto en las condiciones climáticas para las próximas décadas va a originar alteraciones en el funcionamiento actual de las tipologías y de los destinos turísticos tal y como los conocemos en la actualidad, con manifestaciones regionales diversas (Hamilton and Keimb, 2009; ESPON, 2011; IPCC, 2018).

Los efectos posibles del cambio climático son conocidos, desde hace años, por el sector turístico. A la celebración regular, desde 2003, de conferencias internacionales sobre la cuestión, bajo los auspicios de la Organización Mundial del Turismo (Djerba, Davos, Copenhague, Cancún, Durban, Doha, Kenia) y de congresos mundiales sobre aspectos concretos de la relación entre cambio climático y turismo, asimismo organizados por la OMT, (turismo de montaña y nieve; turismo y transporte aéreo), se une la lucha contra el cambio climático en los planes elaborados por los gobiernos en los países desarrollados y las medidas puestas en marcha, desde el ámbito privado del propio sector turístico (UNWTO y UNEP, 2008). Hay, por tanto, un nivel de conocimiento elevado de esta cuestión en consonancia con la importancia de los efectos que puede suponer el cambio climático en esta actividad económica y en los territorios donde se desarrolla. Otra cuestión es el grado real de preparación existente y la efectividad de las medidas desarrolladas. 
Es interesante destacar que en materia de prevención y mitigación del cambio climático se ha pasado de las acciones de "lucha" contra el proceso, basadas, casi en exclusiva, en aspectos energéticos (cambio de modelo, apuesta por energías limpias) a concepciones más integrales donde, además de los aspectos energéticos, cuenta el territorio y sus actividades como principio motor de las actuaciones a llevar a cabo (Dubois and Ceron, 2006). En este contexto es donde la adaptación cobra protagonismo como mecanismo multidisciplinar y multitarea para el planteamiento de soluciones integrales ante un problema global. La propia Organización Mundial del Turismo, en su informe sobre desarrollo sostenible que establece una hoja de ruta con horizonte 2030 para el cumplimiento de los 17 Objetivos de Desarrollo Sostenible de la ONU, señala que el cambio climático es una de las políticas destacadas en el sector en la actualidad y para los próximos años y que ya está motivando la realización de acciones de adaptación por parte de administraciones y empresas (UNWTO, 2017). En concreto, se destacan las actuaciones en instalaciones turísticas (hoteles y apartamentos) orientadas a la reducción de los consumos de agua y energía (UNWTO, 2017, Pulido y López, 2014; Olcina y Vera-Rebollo, 2016a y b).

La actividad turística es una de estas actividades cuyo desarrollo territorial está en estrecha relación con las características físicas del medio donde tiene lugar (López Palomeque et al., 2011, Antón et al., 2011). La Comunidad Valenciana, en la fachada mediterránea española (Figura 2), dispone de unos recursos del medio natural muy idóneas para la implantación de actividades de ocio y recreación que son la base del desarrollo turístico (Vera y Baños, 2010; Vera y Rodríguez, 2012; Olcina y Miró, 2016). Las tierras valencianas acogen una serie de recursos naturales y culturales que han sido aprovechados para el desarrollo turístico a partir de la segunda mitad del siglo XX, en ocasiones de forma intensa y con efectos ambientales irreversibles (Greenpeace y OES, 2018).

Figura 2. Marco geográfico del área de estudio

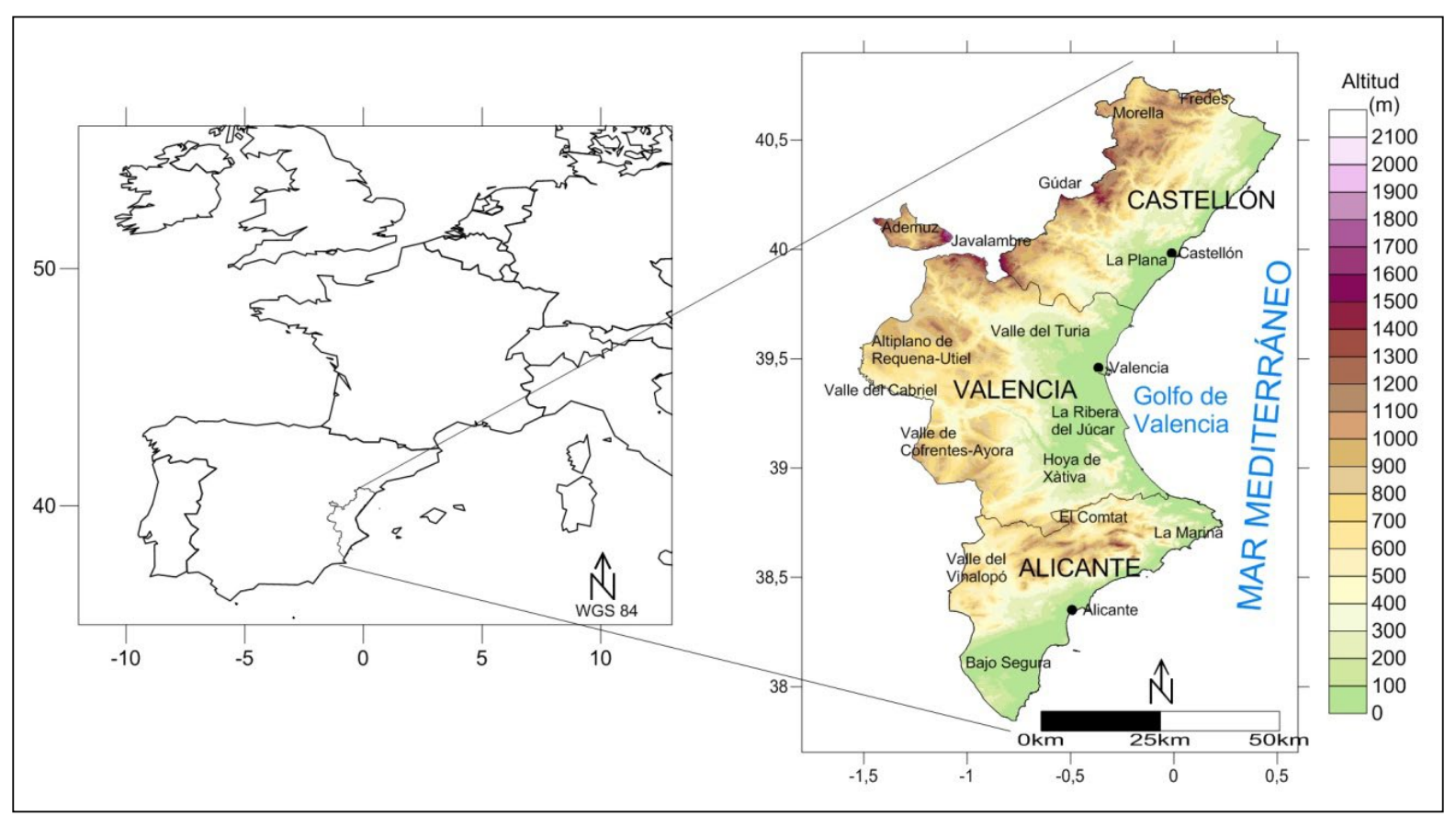

Elaboración propia. 
El clima de la Comunidad Valenciana es un factor determinante de su elevado potencial turístico (Vera Rebollo, 1985; Vera Rebollo, 1987). Pero este valor se ve amenazado, en las próximas décadas, por los efectos del proceso de calentamiento climático actual Bujosa y Roselló, 2011). En el litoral mediterráneo hay tres procesos que tienen relación estrecha con el mecanismo planetario de calentamiento global: 1 ) variaciones estacionales de las precipitaciones (De Luis et al., 2010) y la intensificación de los chubascos, esto es, cambios en la forma de llover (Olcina y Miró, 2017; Miró et al. 2018); 2) el incremento de la temperaturas y, en especial, del calor nocturno, manifestado en las denominadas "noches tropicales" ( $T \underline{a}>20$ 은 C), como elemento de disconfort climático (Olcina et al., 2019); y 3) un preocupante calentamiento de las aguas del mar Mediterráneo occidental (Pastor et al., 2015; Pastor et al., 2018). Los tres están ya corroborados por los datos científicos. Ya no son supuestos, son manifestaciones claras de cambio climático en esta región del este de España (Aemet, 2015).

Los tres tienen efectos directos en las actividades económicas y muy especialmente en el turismo de "sol y playa" que es una de las fuentes de ingreso económico principal de la Comunidad Valenciana. Los efectos, ya notables, de los cambios en las temperaturas extremas y, por tanto, en el confort climático va a condicionar el desarrollo de medidas de adaptación del sector turístico, tanto en destinos como en establecimientos (Rico et al, 2009; Rico et al., 2013; Olcina et al., 2016c; Gómez Royuela, 2016).

El presente trabajo ahonda en el impacto del incremento de las temperaturas, tanto máximas diurnas como mínimas nocturnas, como factor fundamental de pérdida del confort climático. El estudio de confort térmico ha merecido multiples trabajos en los últimos años, en el contexto de calentamiento térmico planetario (Vardoulakis, et al., 2013; Royé y Martí, 2015). En el litoral mediterráneo español destacan los trabajos dedicados al análisis de la evolución térmica en Barcelona, debido a la importancia del tamaño de las ciudades en las modificaciones locales de las temperaturas (Martín Vide et al., 2015; Moreno y Serra, 2016; Royé, 2017; Salvati et al., 2017; Barros Pozo y Martín Vide, 2018). Se trata de estudios que recuperan las aportaciones clásicas sobre "isla de calor" desarrolladas en este ámbito (Carreras et alt., 1990; Moreno, 1993).

Para el estudio del confort térmico existen diferentes índices -índice de temperatura efectiva, índice de Hill, diagramas bioclimáticos de Olgyay y de Givoni, índices PMV y PPDadaptados para diferentes objetivos de investigación: confort humano, diseño urbano y de edificios (Fernández García, 1994; Blasco et al. 2007). En este trabajo se ha manejado, por la disponibilidad de datos climáticos de base en alta resolución espacial, el índice de Confort Climático de Mieczkowski para valorar la situación actual y hacer proyección hacia final de siglo. El empleo de este índice ha sido testato en trabajos anteriores, con resultados adecuados (Miró Pérez et al., 2016c) y se muestra idóneo para las aproximaciones sobre aptitud turística de un territorio (Millán y Fernández, 2018).

El trabajo cartografía a escala de detalle y estudia la distribución territorial del confort térmico en la Comunidad Valenciana, a partir del análisis de las temperturas máximas y de las "noches tropicales" ( $T^{\underline{a}}>\mathbf{2 0}$ ㅇ C). Se analizan los factores geográficos que afectan al confort térmico y se proyecta su situación hacia finales del presente siglo en el contexto del actual proceso de calentamiento climático. Se trata de un estudio fundamental para el diseño de 
acciones de adaptación de los destinos y alojamientos turísticos en los próximos años en el territorio valenciano. Esta medidas de adaptación, llevadas a cabo por la administración pública -regional y local- y el sector privado deben incluir actuaciones de diseño urbano, de aclimatación de edificios -hoteles y apartamentos-, de gestión eficaz de los consumos energético y de agua, de modificación de las temporadas turísticas y de comunicación sobre acciones a desarrollar en un contexto de cambio climático a turistas y residentes.

\section{DATOS Y MÉTODOS}

En el presente estudio se ha hecho uso del Índice de Confort Climático de Mieczkowski (Mieczkowski, 1985), conocido por sus siglas TCI, para llevar a cabo una evaluación a escala de detalle de los cambios previstos en el confort climático durante el siglo XXI para la Comunitat Valenciana, dentro del contexto de cambio climático previsto por las proyecciones.

Se ha llevado a cabo una evaluación estacional agrupando los trimestres del siguiente modo: primavera (marzo, abril y mayo), verano (junio, julio y agosto), otoño (septiembre, octubre y noviembre), e invierno (diciembre, enero y febrero).

En primer lugar se calculó el TCl inicial para un periodo de referencia que da cuenta de la situación actual (inicio del siglo XXI) de confort climático para Alicante, utilizando para ello los datos del periodo 1948-2014. A continuación se ha aplicado el cambio previsto para las distintas variables que componen el TCl, a fin de calcular la hipotética situación que adoptará el TCl a finales del siglo XXI, y poder evaluar el cambio previsto.

\section{1. Índice de Confort Climático de Mieczkowski}

De las múltiples herramientas e índices que la comunidad científica ha desarrollado para evaluar de algún modo la aptitud turística que ofrece un clima en base a sus temperaturas, insolación, precipitaciones, humedad, viento, etc., hemos empleado el Índice de Confort Climático de Mieczkowski ( $\mathrm{TCl}$ ). Aunque hoy existen otros índices que tienen en cuenta más factores, el uso del $\mathrm{TCl}$ es el que se ajusta a los datos que disponemos en alta resolución espacial. Así, otros índices requieren información horaria en temperaturas u otras variables, mientras que la información disponible en alta resolución espacial, a cambio de dicha resolución, se limita a valores acumulados, medios, mínimos y máximos diarios. Sobre dichos valores se obtiene un $\mathrm{TCl}$ promedio mensual, que en este caso, se reduce a estacional. Éste se determina por la suma de 5 subíndices. Y se define como:

$$
\mathrm{TCl}=8 \mathrm{CID}+2 \mathrm{ClA}+4 \mathrm{R}+4 \mathrm{~S}+2 \mathrm{~W}
$$

donde $\mathrm{CID}$ es el índice de confort diurno, determinado por la temperatura y humedad a la hora de mayor calor (temperatura máxima y humedad mínima diarias medias); CIA es el subíndice de confort medio, determinado por la temperatura y humedad medias; $\mathrm{R}$ es el subíndice pluviométrico determinado por la precipitación total media (mensual, estacional o anual, según resolución temporal de cálculo del TCI); $\mathrm{S}$ es la cantidad efectiva media de horas de sol al día; y $W$ es la velocidad media del viento. 
Estos subíndices no se expresan en las unidades propias de las variables climatológicas utilizadas, sino que sirven para ponderar un valor dentro de una horquilla fija que va de 0 (desfavorable) a 5 (óptimo) para R, S y W, que en el caso del CID y CIA se establece entre -3 y 5. La tabla 1 sirve para obtener dicho valor de los subíndices $\mathrm{R}, \mathrm{S}$ y $\mathrm{W}$ a partir del valor original de las variables, mientras que el diagrama de la Figura 3 muestra cómo se obtiene el valor de los subíndices de confort CID y CIA.

Tabla 1: Criterios para evaluar el valor de los subíndices $\mathrm{R}, \mathrm{S}$ y $\mathrm{W}$ del $\mathrm{TCl}$

\begin{tabular}{|c|l|c|l|}
\hline Puntos & $\mathrm{R}(\mathrm{mm})$ & $\mathrm{S}(\mathrm{h})$ & $\mathrm{W}(\mathrm{m} / \mathrm{s})$ \\
\hline 5.0 & $\leq 14.9$ & $>10$ & $<0.8$ \\
\hline 4.5 & $15.0-29.9$ & $9-10$ & $0.8-1.5$ \\
\hline 4.0 & $30.0-44.9$ & $8-9$ & $1.6-2.5$ \\
\hline 3.5 & $50.0-59.9$ & $7-8$ & $2.6-3.3$ \\
\hline 3.0 & $60.0-74.9$ & $6-7$ & $3.4-5.4$ \\
\hline 2.5 & $75.0-89.9$ & $5-6$ & $5.5-6.7$ \\
\hline 2.0 & $90.0-104.9$ & $4-5$ & $6.8-7.9$ \\
\hline 1.5 & $105.0-119.9$ & $3-4$ & - \\
\hline 1.0 & $120.0-134.9$ & $2-3$ & $8.0-10.7$ \\
\hline 0.5 & $135.0-149.9$ & $1-2$ & - \\
\hline 0 & $\geq 150$ & $0-1$ & $>10.7$ \\
\hline
\end{tabular}

Fuente: Mieczkowski, 1985.

Figura 3. Diagrama para el cálculo de los subíndices de confort CID y $\mathrm{CIA}$ del TCI

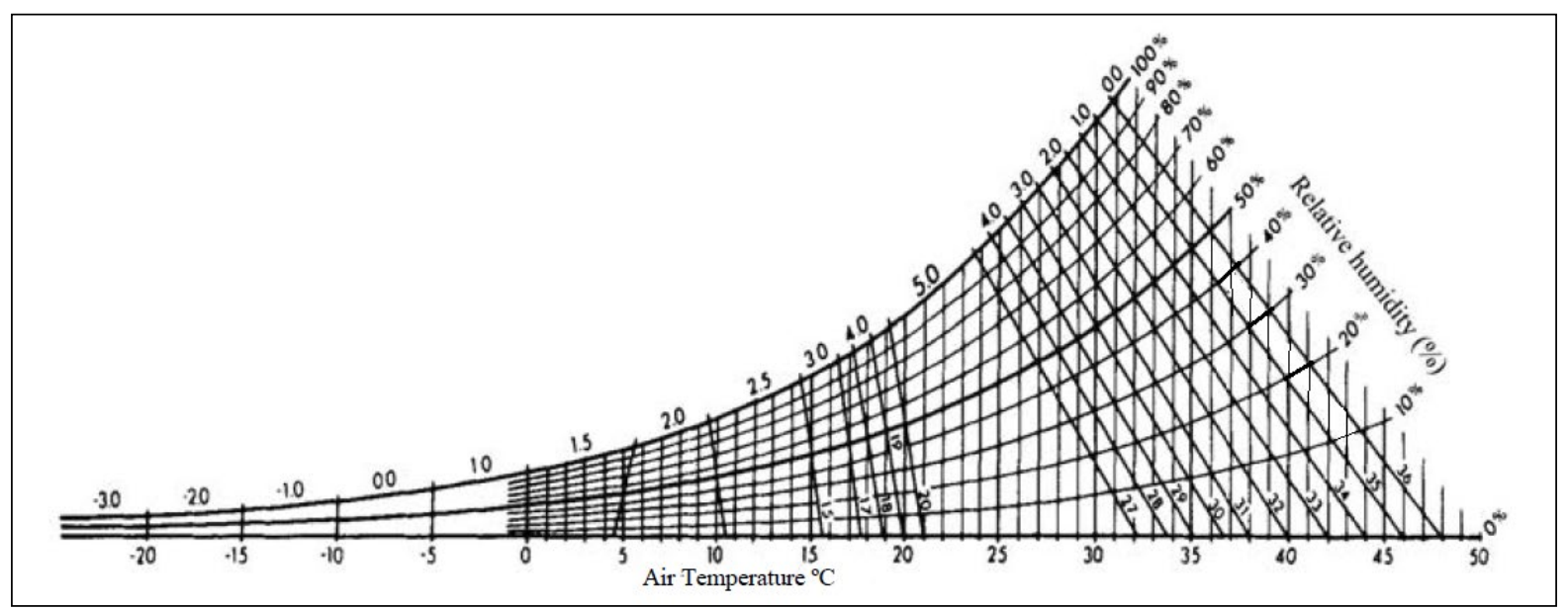

Fuente: Mieczkowski, 1985.

Ello supone, al aplicar la fórmula anterior, que el valor máximo posible para el $\mathrm{TCl}$ es 100 (valor idealmente óptimo). De modo que, según el TCl resultante, se establece el grado de confort que define la aptitud turística del clima de acuerdo a la Tabla 2. 
Tabla 2: Categorías del TCI

\begin{tabular}{|l|l|}
\hline Valor TCI & Categoría \\
\hline $90-100$ & Ideal \\
\hline $80-89,9$ & Excelente \\
\hline $70-79,9$ & Muy bueno \\
\hline $60-69,9$ & Bueno \\
\hline $50-59,9$ & Aceptable \\
\hline $40-49,9$ & Marginal \\
\hline $30-39,9$ & Desfavorable \\
\hline $20-29,9$ & Muy desfavorable \\
\hline $10-19,9$ & Extremadamente desfavorable \\
\hline$<10$ & Imposible \\
\hline
\end{tabular}

Fuente: Mieczkowski, 1985.

\subsection{Datos empleados en el cálculo del $\mathrm{TCl}$ de referencia}

La temperatura es la variable que más fluctúa en la vecindad espacial debido a su dependencia de las variaciones de la altitud. Por lo que es la variable más decisiva para una correcta estimación a fina escala del TCI. Por ello, se ha hecho uso de la base de datos SDSITVC (Miró, 2014; Miró et al., 2015, 2016a y 2016b) como fuente de temperaturas máximas y mínimas diarias a fina escala. Dicha base de datos cubre la Comunitat Valenciana y áreas limítrofes con una resolución de 90 m para el periodo completo 1948-2011 (actualizado a 2014) con homogeneidad y sin lagunas.

Para las precipitaciones también se ha hecho uso de otra base de datos procesada para ofrecer datos diarios completos, homogéneos y a fina escala, en este caso para el periodo completo 1955-2016, como es la obtenida para el conjunto de las Confederaciones Hidrográficas del Júcar y Segura a través del método NLPCA+EOF-QM (Miró et al., 2017, 2018). En este caso se dispone de datos reconstruidos con una resolución espacial de $200 \mathrm{~m}$.

Las mencionadas bases de datos de temperaturas y precipitaciones se basaron principalmente en la información derivada de la red secundaria de observatorios de AEMET. Pero el resto de variables necesarias para el cálculo del TCl (humedad, insolación y viento) ya no están igualmente disponibles para dicha red y por un periodo largo, a excepción de unos pocos observatorios disponibles de primer orden, insuficientes para una cartografía de detalle. Por ello, como fuente para estas variables, se ha hecho además uso de la red de estaciones automáticas del IVIA-SIAR ${ }^{1}$, utilizando los datos de 20 estaciones, observados entre 1999 y 2014.

Cabe indicar que, para poder realizar el cálculo espacial del TCI fue necesario interpolar o re-interpolar previamente cada una de las variables utilizadas según las mismas características del SDSITVC (temperaturas), esto es, una resolución espacial de 90 m (coordenadas UTM

1. Instituto Valenciano de Investigaciones Agrarias - Sistema de Información Agroclimática para el Regadío (http:// eportal.mapa.gob.es/websiar/Inicio.aspx) 
huso 30). La SDSITVC está originalmente interpolada mediante kriging ordinario, mientras que para la interpolación de las precipitaciones y resto de variables se utilizó método de interpolación polinómica desarrollado en Wang et al. (2014).

Si bien los periodos de observación no son coincidentes para todas las variables, por su longitud podemos asumir que permiten una caracterización del $\mathrm{TCl}$ lo suficientemente representativa de su estado inicial al comienzo del siglo XXI.

\subsection{Calculo de la proyección del TCI para el periodo 2071-2100}

El cálculo de la proyección futura del $\mathrm{TCl}$ se ha realizado sobre la base de un cambio causado por el forzamiento térmico asociado al cambio climático, esto es, bajo la premisa de que las temperaturas van a ser las principales responsables de cambios en el grado de confort, y siendo también que éstas son la variable de mayor peso en el TCl. Además, el cambio previsto en las temperaturas es el que está mejor establecido por parte de los modelos de proyección climática. Por el contrario, las proyecciones para precipitaciones y otras variables, aunque muestran escenarios con un mayor número de días secos y sequías, arrojan resultados geográficamente más dispares y más incertidumbres (Argüeso, 2011; Brunet et al., 2009; IPCC, 2014; Morata, 2014; Miró, et al., 2018). Además, para las otras variables como la humedad, la insolación o el viento, son escasas las proyecciones existentes y tienen relativamente menor peso en el TCl, así como su impacto en el cambio climático tiene mayor grado de incertidumbre. Por tanto, para el cálculo de la proyección se ha decidido ponderar únicamente el cambio de confort atribuible a un cambio de temperaturas, dejando por defecto sin cambios el resto de variables.

Para calcular el cambio térmico al periodo 2071-2100, en primer lugar se ha tomado la información a fina escala del SDSITVC sobre patrones espaciales de cambio térmico ya en curso en las últimas décadas, y que han sido bien establecidos en Miró et al. (2015, 2016a, 2016b). A continuación, la magnitud de dichos patrones espaciales se ha proyectado al futuro aplicando el forzamiento térmico previsto por AEMET en su modelo de regionalización AR5-IPCC para el periodo 2071-2100 (http://www.aemet.es/es/serviciosclimaticos/cambio climat). El resultado es una proyección de cambio basada en los patrones espaciales de cambio a fina escala ya detectados actualmente, pero redimensionada según la estimación general de cambio futuro en la región proporcionada por la proyección de AEMET.

\section{RESULTADOS}

Los estudios recientes han puesto de manifiesto tendencias significativas hacia el ascenso en las temperaturas y los episodios de calor, en general sobre el este de la península Ibérica, y en concreto la Comunitat Valenciana, desde mediados del siglo XX a la actualidad (Miró et al., 2006, Brunet et al., 2009, Sánchez-Lorenzo et al. 2011, El Kenawy, et al. 2012, Del-Río et al., 2012, Miró et al., 2015, 2016a, 2016b, Royé, 2017, Olcina et al., 2019). Un ascenso que, tras la pertinente reconstrucción, homogeneización de datos y filtrado del efecto urbano, se muestra más notorio en las temperaturas máximas y particularmente en las zonas elevadas del interior y montañosas de la Comunitat (Miró et al., 2015 - Figura 4). 
Figura 4. Relieve de la Comunitat Valenciana (izquierda), junto con los cambios a fina escala registrados por las temperaturas máximas (centro) y mínimas (derecha) entre 1948 y 2011

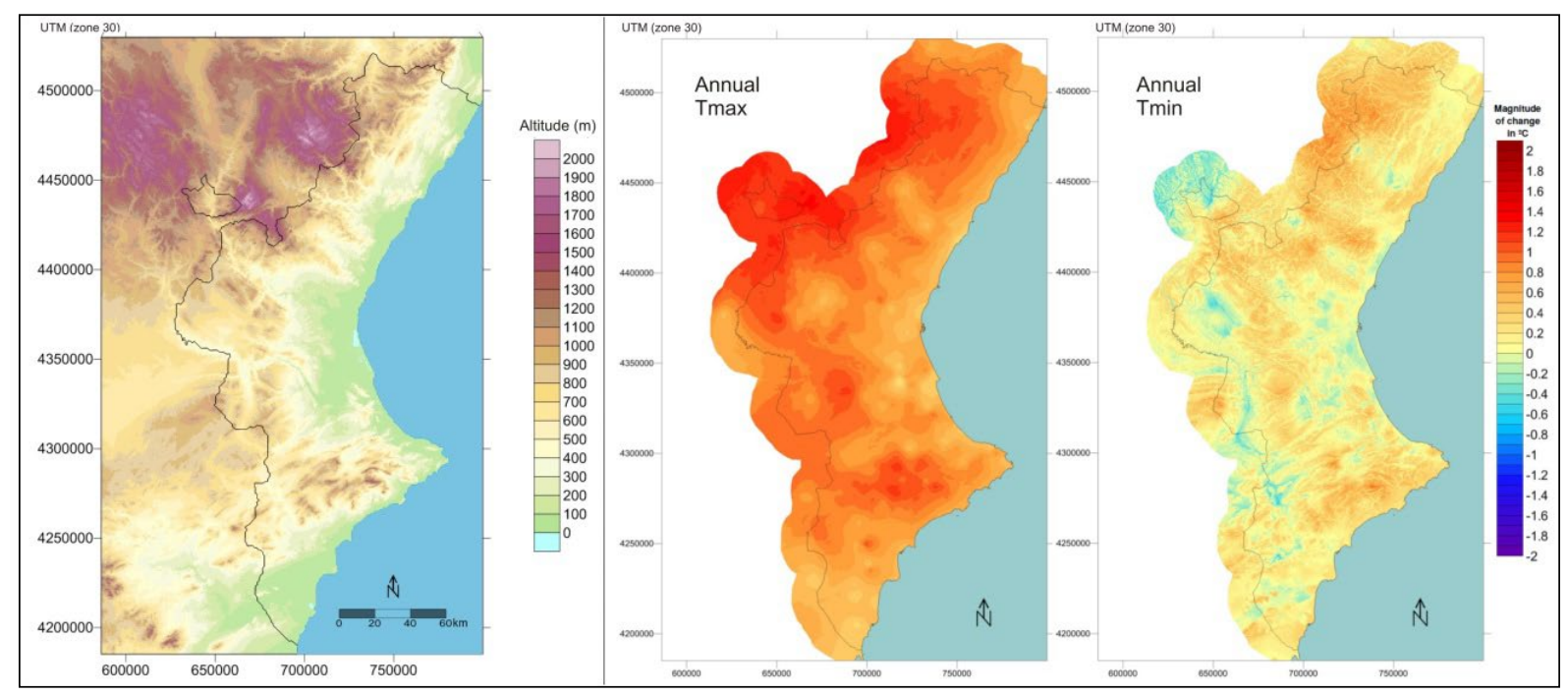

Fuente: Miró et al. (2015) - base de datos SDSITVC.

Los estudios a muy fina escala (90 m. de resolución espacial) realizados a partir de la base de datos SDSITVC en Miró et al. (2015, 2016a y 2016b) ponen de relieve cambios en curso muy relevantes sobre las zonas montañosas del interior de la Comunitat asociados a un importante ascenso de las temperaturas máximas y un aumento de los episodios de inversión térmica en las temperaturas mínimas. Este aumento es mayor entre la primavera y la primera mitad del verano, alcanzándose las mayores tasa de calentamiento en las máximas de Junio (Figura 5).

Esto conlleva cambios importantes hacia un incremento de temperaturas máximas tórridas en verano, cuyo periodo de aparición también tiende a expandirse hacia la segunda mitad de primavera, especialmente en Junio. Las áreas en que estas temperaturas tórridas se dan con mayor frecuencia y fuerza, como los valles y depresiones relativamente interiorizados al abrigo de las brisas (Hoya de Xàtiva, interior del Bajo Segura, Valle de Cofrentes-Ayora, etc.), son las que acusarían mayormente un incremento de temperaturas máximas poco propicias a las actividades en el exterior. 
Figura 5. Cambios a fina escala registrados por las medias mensuales de las temperaturas máximas entre 1948 y 2011

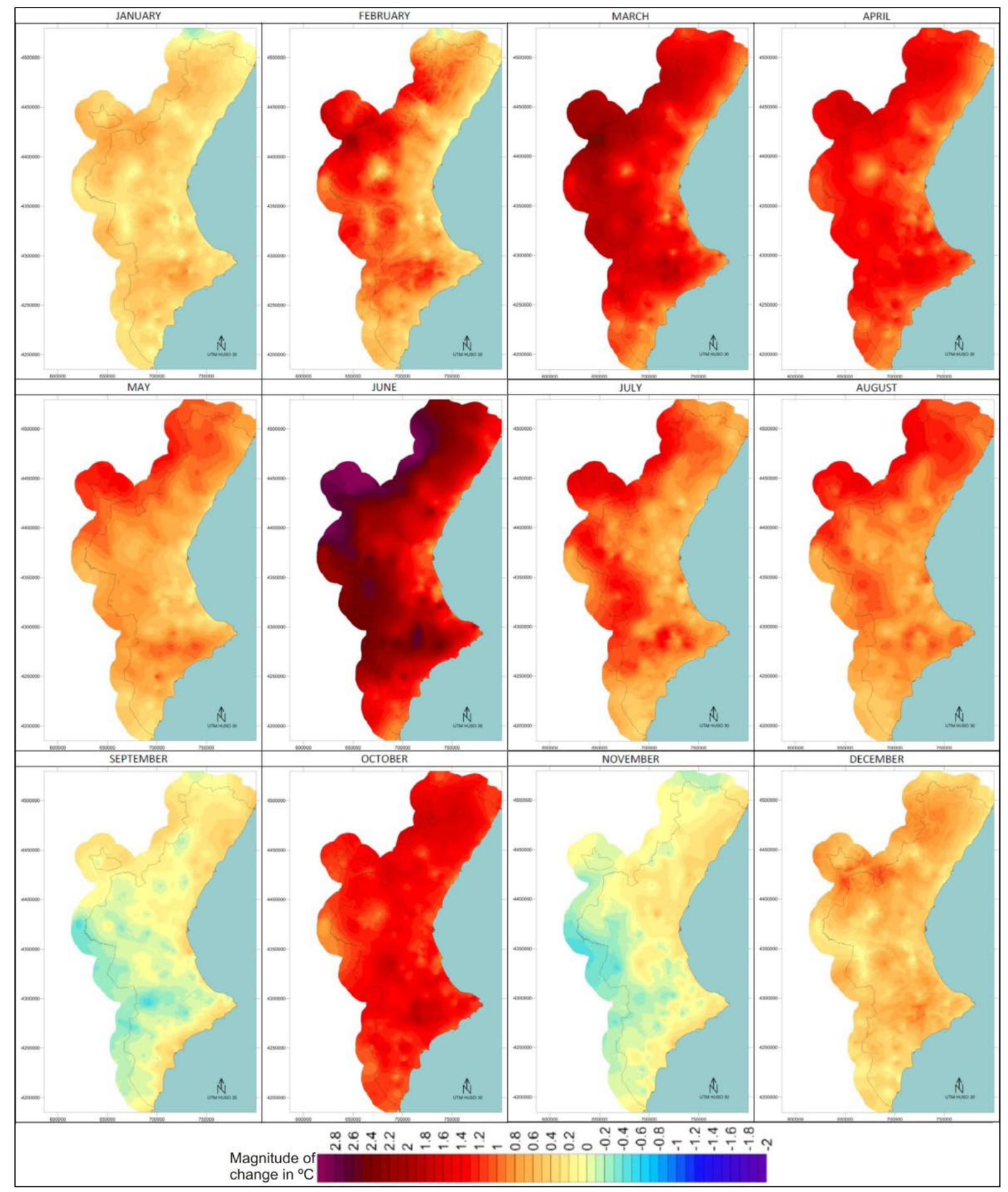

Fuente: Miró et al. (2015) - base de datos SDSITVC. 
Mientras que el ascenso de las temperaturas máximas parece tener sus mayores impactos en los sectores del interior, la franja litoral es más susceptible a otro fenómeno que se está incrementando con el cambio climático. Se trata de las noches tropicales, como aquellas en que la temperatura mínima se mantiene por encima de $20^{\circ} \mathrm{C}$. Así, unas temperaturas mínimas demasiado altas son causa de escaso confort nocturno, dificultades para conciliar el sueño, además de propiciar la expansión de plagas y vectores infecciosos, debido a la falta de horas de frío necesarias para su control.

Con el cambio climático, la frecuencia de noches tropicales está aumentando con fuerza en toda la franja litoral y prelitoral de la Comunitat (Olcina et al., 2019), como muestra la Figura 6.

Figura 6. Tendencia en la frecuencia anual de noches tropicales registrada entre 1950 y 2014

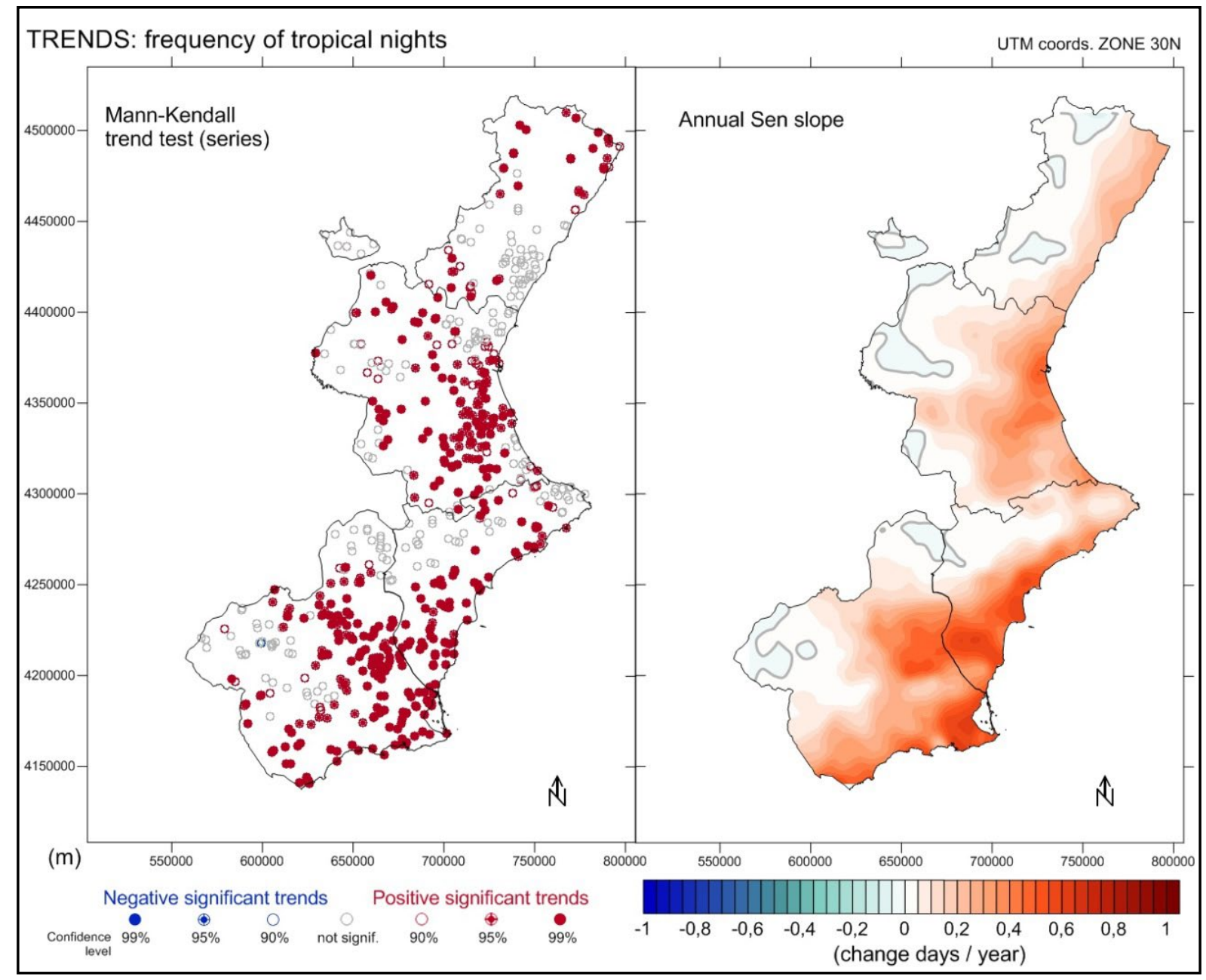

Fuente: Olcina et al. (2019). 
No sólo aumenta la frecuencia de noches tropicales, sino también las rachas con tres o más noches tropicales consecutivas; se amplía el periodo anual con su aparición (particularmente en primavera); así como aumenta su intensidad por encima de $20^{\circ} \mathrm{C}$ (hacia noches tórridas con mínimas incluso de 25C o más), según los resultados obtenidos en Olcina et al. (2019).

En este caso, si bien la influencia del Mar Mediterráneo y sus brisas atenúa sobre el litoral el incremento de las máximas que se da en el interior, la tendencia al ascenso de la temperatura superficial marina (SST) en la cuenca mediterránea (Pastor et al., 2018) está también detrás de una dificultad mayor al enfriamiento nocturno conllevando el aumento de las noches tropicales. El efecto de la isla de calor urbana, que también se ha ido incrementando notablemente en el litoral durante los últimos 6 o 7 decenios, se suma a este efecto. Precisamente, en Pastor et al. (2018) se han señalado tendencias de calentamiento de la SST de hasta $2^{\circ} \mathrm{C}$ en los meses de verano, especialmente Junio, entre 1982 y 2016, que sin embargo son mucho más débiles en Otoño, lo cual coincide bastante bien con las tendencias estacionales y mensuales registradas por las temperaturas terrestres sobre la Comunitat según se reportó en Miró et al. (2015, 2016a -Figura 5).

La Figura 7 muestra el resultado de la estimación del TCI de referencia, que representa el punto de partida representativo de los últimos decenios. 
Figura 7. $\mathrm{TCl}$ de referencia (actual) calculado para cada estación del año

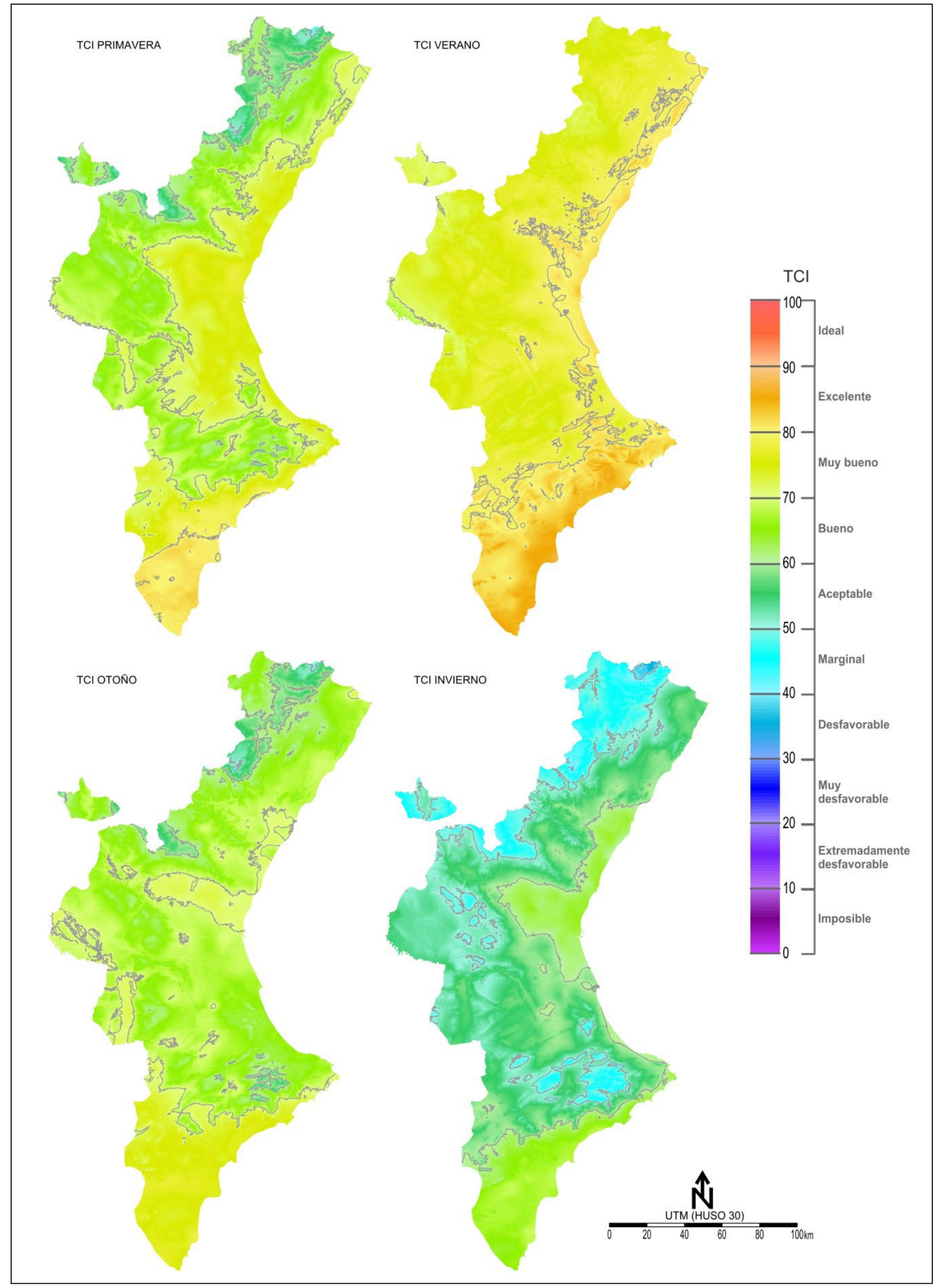


Tal como cabría esperar, la estación estival es la que proporciona mejores niveles de confort en el TCl. Toda la franja litoral bajo la influencia de las brisas de origen marino, e incluso gran parte de áreas prelitorales del tercio Sur, gozan de un $\mathrm{TCl}$ en la categoría de 'excelente' durante el verano. Las áreas interiores bajan un nivel de confort, dado que aquí las temperaturas máximas caniculares se disparan más y la oscilación térmica diurna es mayor, pero se mantienen en la categoría de 'muy bueno'. Como única excepción sólo quedan puntos muy interiores de los valles de Cabriel y Turia, coincidiendo con las áreas donde se producen las mayores oscilaciones térmicas diurnas de la Comunidad Valenciana (Miró et al., 2015), y que quedan en la categoría de 'bueno'.

Por el contrario, el invierno registra los niveles de confort más bajos y, además, presenta las mayores diferencias entre el interior montañoso y el litoral, particularmente en Castellón. Sin embargo, a pesar de tratarse de la estación fría, todavía la mayor parte de la franja litoral de la Comunidad, el prelitoral Norte de Valencia y la mitad Sur de Alicante mantienen un TCl en la categoría de 'bueno'. Si bien la mayor parte del territorio cae en la categoría de 'aceptable', mientras que sólo las zonas más elevadas y húmedas de Alicante y Valencia, y aún gran parte del interior y Norte de Castellón, pasan a tener una categoría de 'marginal'. Incluso aparece un $\mathrm{TCl}$ 'desfavorable' en un reducto muy al Norte de Castellón, en torno a Fredes.

Respecto de las estaciones equinocciales, con niveles de confort a caballo entre invierno y verano, la primavera presenta niveles de confort algo mejores que en el otoño, pero también más diferencias entre el interior montañoso y el litoral. De hecho la primavera presenta ya un TCl 'excelente' al Sur de Alicante (litoral Sur y Vega Baja del Segura). También presenta una categoría de 'muy bueno' en el resto de la franja litoral y la mayor parte de sectores prelitorales de la Comunitat. La mayor parte de zonas altas interiores presentan aún un TCl en la categoría de 'bueno', aunque en el interior de Castellón y Ademuz quedan zonas en la categoría de 'Aceptable'.

En otoño, sin embargo, quedan más desdibujadas las diferencias entre el interior y el litoral, seguramente a causa de la mayor probabilidad de lluvias otoñales litorales de origen mediterráneo. Con todo, la mayor parte de Alicante (excepto su tercio Norte) presenta un $\mathrm{TCl}$ 'muy bueno', mientras que la mayor parte del territorio de la Comunitat queda en un TCl 'bueno'. Sólo baja a 'aceptable' en los sectores más altos de Castellón, y sobre las montañas interiores de la Marina y El Comtat, en el Norte de Alicante.

Partiendo del $\mathrm{TCl}$ de referencia (Figura 7) como base para el cálculo de cambios futuros, la Figura 8 muestra la magnitud de cambio previsto para el periodo 2071-2100 expresado en las unidades propias del TCl, o sea, el aumento o disminución sobre el valor de 0 a 100 que presentaba el $\mathrm{TCl}$ de referencia. 
El primer hecho que destaca en esta proyección es una acusada pérdida de confort para el caso del verano, lo que puede asociarse a unas temperaturas por encima del nivel óptimo de confort térmico, bien sea por máximas excesivas (preferentemente en el interior) o bien por la frecuencia de noches tropicales (preferentemente en el litoral). La pérdida es mayor en los valles y hoyas interiores del centro-Sur de la Comunitat, especialmente en el interior de Valencia (hasta 8-9 puntos localmente), y del Norte de Alicante (hasta 7 puntos localmente), asociada a las temperaturas máximas. Sin embargo, también es cercana a los 5 puntos de pérdida de confort en la mayor parte de las provincias de Valencia y Alicante, y los valles prelitorales de Castellón. Todas las áreas litorales pierden al menos 3 o 4 puntos en confort, en este caso con una mayor responsabilidad en el aumento de las noches tropicales. Sólo ciertas zonas montañosas, especialmente las prelitorales más expuestas a la regulación de las brisas mar-valle-ladera y su pérdida de temperatura con su ascenso en altitud, acusarían un cambio débil o no significativo (los cambios reflejados en el TCI no serían estadísticamente significativos en general cuando han quedado por debajo de \pm 1.2 puntos, según el intervalo de confianza del 95\%).

El caso opuesto al verano ocurre para el invierno, ya que la tendencia ahora es hacia una mejora de confort en toda la Comunitat sin excepción (entre 1,5 y 6 puntos). 
Figura 8. Cambio previsto en unidades del TCI para el periodo 2071-2100 con respecto al TCI de referencia, según la proyección climática utilizada en el estudio

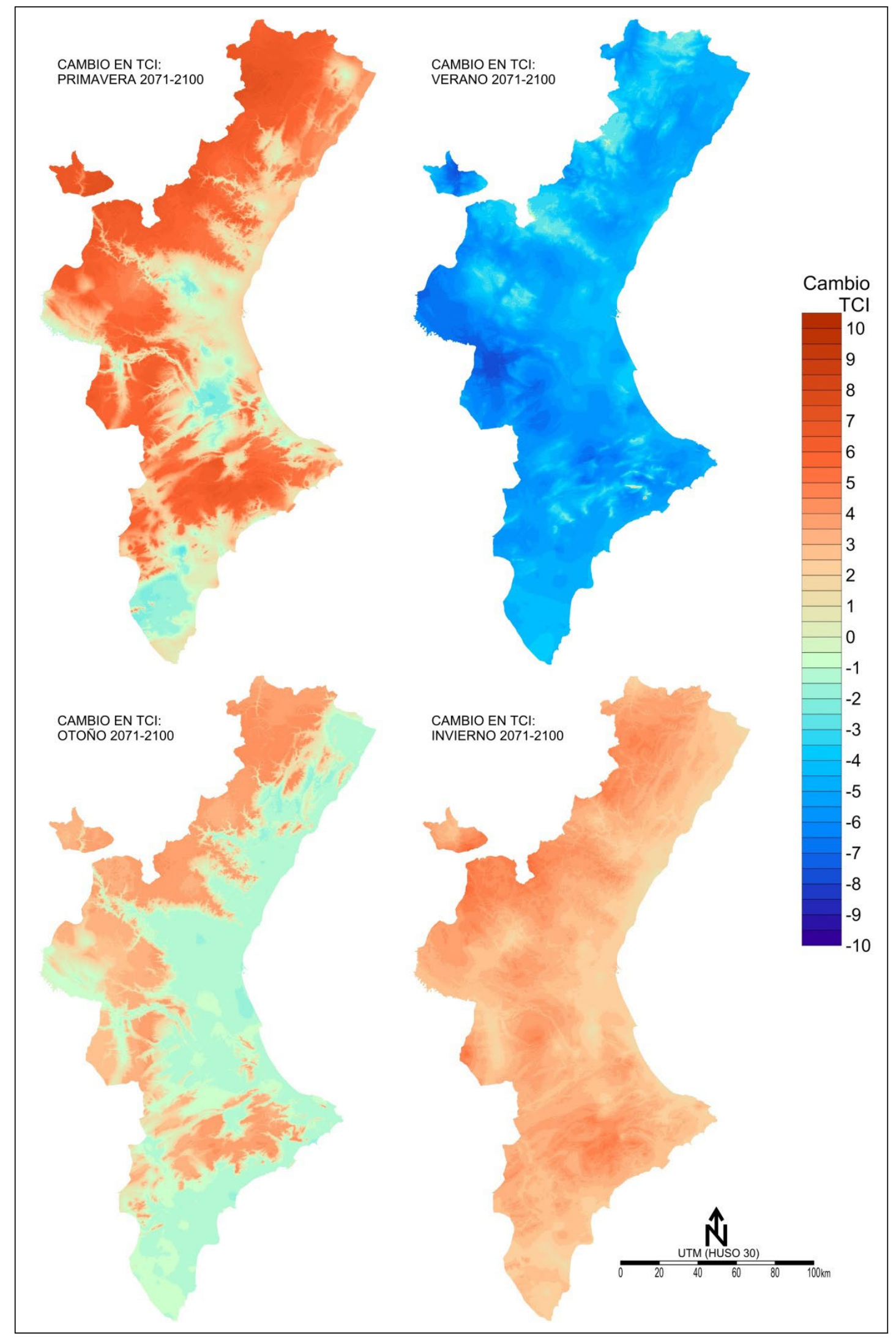


Por otro lado, los mayores aumentos relativos de confort se esperan para las áreas montañosas y partes altas, no sólo en invierno sino también, en mayor medida si cabe, en otoño y primavera. Además, en estas estaciones de transición se observan tendencias opuestas entre las tierras altas (aumento de confort) y las tierras bajas y litorales (sin cambios significativos o bien débiles). La diferencia es más acusada en primavera, cuando la proyección señala un acusado aumento de confort ( 5 a 8 puntos en $\mathrm{TCl}$ ) en las partes altas por encima de $500 \mathrm{~m}$. en el Sur, e incluso a menores altitudes en el Norte, siempre más pronunciado con una mayor altitud. Sin embargo, en el litoral los cambios son más débiles o incluso no significativos, apareciendo débiles pérdidas de confort (cambios generalmente no significativos) en llanuras prelitorales relativamente interiorizadas de la mitad Sur.

En otoño los cambios previstos son más débiles, pero también se espera un débil a moderado aumento de confort (no superior a 4 puntos) en las tierras altas del interior, mientras que todo el litoral, llanos prelitorales y zonas de valle abiertas quedan con cambios muy débiles (pérdidas en la mayoría de casos no significativas).

El análisis de los cambios proyectados en el $\mathrm{TCl}$ de acuerdo a los resultados anteriores apunta, como hecho más importante, a una pérdida clara de confort en verano que se vería compensada por una relativa mejoría de los niveles de confort en los meses fríos, sobretodo en invierno y primavera. La Figura 9 muestra el TCl recalculado tras aplicar los cambios proyectados en la Figura 8. De modo que se muestra cómo se espera que el TCl y sus categorías queden para el periodo de proyección 2071-2100. Su comparación con el TCl de referencia (Figura 7) señala modificaciones claras en la distribución de los niveles de confort. Así las pérdidas de confort en verano, junto con su aumento en zonas interiores para la primavera, dan como resultado que ahora tanto el verano como la primavera quedan a la par como estaciones con una mejor aptitud turística, predominando en general un $\mathrm{TCl}$ en la categoría de muy bueno. Sin embargo sólo se mantiene la categoría de 'excelente' en el litoral más al Sur, siendo notable su reducción espacial en verano con respecto al periodo de referencia. 
En invierno se destaca bastante la mejora del $\mathrm{TCl}$ en todo interior montañoso de la Comunitat Valenciana. De hecho desaparece el enclave que quedaba bajo la categoría de 'desfavorable' al Norte de Castellón, mientras que todos los sectores bajo la categoría de 'marginal' se reducen notablemente. Asimismo también destaca la aparición de la categoría de 'muy bueno' en puntos litorales de Alicante, cuando en el periodo de referencia no llegaba a estar presente en invierno. La categoría de 'bueno' también gana peso en toda la franja litoral y prelitoral (Miró et al., 2015).

Y en otoño se aprecian también mejoras en la categoría del TCl en zonas altas del interior, donde la categoría 'aceptable' se reduce a muy pocos enclaves, en favor de la categoría de 'bueno'. Mientras que en el resto los cambios son ya poco importantes.

De manera que, la estación más apta para la actividad turística ya no se centraría sólo en el verano, sino que también tomaría protagonismo la primavera, beneficiada tanto por unos mejores niveles de confort cuasi estivales como por la pérdida relativa de confort en verano. Detrás de estos cambios tenemos fundamentalmente causas térmicas, de acuerdo a la información señalada en los apartados 1.1 y 1.2. Así, la tendencia al aumento de las temperaturas máximas (Miró et al., 2015) hasta niveles poco confortables está principalmente detrás de la perdida de confort estival en los valles interiores, o relativamente interiorizados, peor regulados por las brisas. Mientras que el aumento de las noches tropicales y mínimas elevadas en zonas urbanizadas litorales (Olcina et al., 2019), relacionado con un aumento de la SST mediterránea (Pastor et al., 2017), estarían mayormente detrás de la pérdida de confort estival en el litoral. 
Figura 9. TCl proyectado al periodo 2071-2100 para cada estación del año

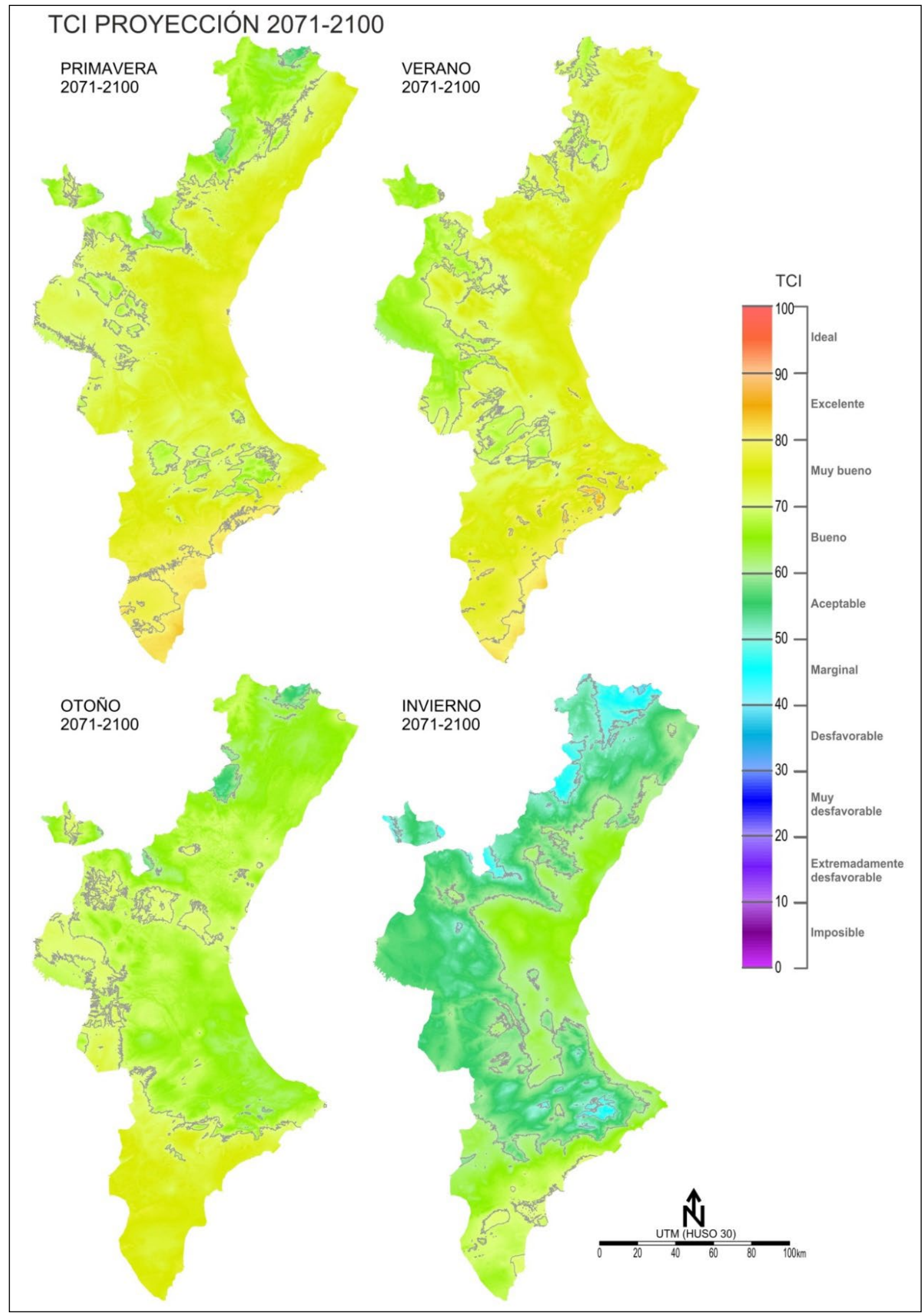




\section{DISCUSIÓN: PROPUESTAS DE ADAPTACIÓN ANTE EL CAMBIO DE CONFORT TÉRMICO EN LA ACTIVIDAD TURÍSTICA DE LA C. VALENCIANA}

El escenario de cambio climático futuro obliga a los destinos turísticos a adaptarse a la nueva realidad si se quiere mantener la actual competitividad. Se trata de un proceso de medio y largo plazo que debe comenzar a planificarse ahora para evitar mayores costes económicos, sociales y territoriales dentro de unas décadas. En los últimos años se han desarrollado acciones de mitigación y adaptación de la actividad turística ante el cambio climático en diversos países del mundo y, entre ellos también en España y en alguna de sus Comunidades Autónomas (Olcina y Vera-Rebollo, 2016b).

A los efectos del calentamiento en el propio funcionamiento del clima regional se une el previsible impacto económico que el cambio climático puede suponer en la actividad turística de la Comunidad Valenciana. A escala global, es notable la carencia de modelos globales de pérdida económica en la actividad turística, a causa del cambio climático. Los informes oficiales, como los de la UNWTO o del IPCC, o los estudios realizados señalan la importancia de la actividad a partir de las cifras macroeconómicas mundiales y el impacto que una alteración importante de las condiciones climáticas supondría en los movimientos de turistas a escala global (UNWTO, 2017; IPCC 2018). Incluso las aproximaciones regionales y locales siguen el mismo esquema sin ofrecer cifras concretas sobre dicho impacto. Preocupa, especialmente, las alteraciones en la cuota de mercado que la subida de temperaturas puede causar en las modalidades de actividad turística de las regiones del mundo; y se manejan modelos de oferta y demanda que tienen en cuenta el cambio en las condiciones térmicas de los territorios objeto de análisis. Los trabajos de investigación de los autores referentes en esta cuestión (Scott, 2008; Scott et al., 2011; Gössling, Petters and Scott, 2008; Hamilton and Keimn, 2009; Dubois and Ceron, 2006) abundan en esta línea, que asimismo se manifiesta en informes oficiales elaborados en los últimos años por parte de la ONU o la propia Organización Mundial del Turismo. Así, por ejemplo, Bigano et al. (2008) han analizado los efectos del cambio climático en la actividad turística de la cuenca del Mediterráneo, a partir de la aplicación del modelo turístico de Hamburgo (HTM), y señalan una pérdida de llegada de turistas, para el horizonte 2100 , en todos los países ribereños de la cuenca mediterránea que alcanzan porcentajes superiores al $40 \%$.

En Europa, una valoración actualizada del impacto económico del cambio climático en la actividad económica, incluido el turismo, se ha realizado en el informe PESETA II (JRC, 2014), recientemente actualizado en el informe PESETA III (JRC, 2018). A partir del manejo de 4 modelos climáticos se ha calculado el efecto del calentamiento global en diversos sectores económicos, entre ellos el turismo. Se ha manejado básicamente dos escenarios de emisiones: incremento de temperatura de $2 \circ$ C (RCP 4.5), contemplado en el Acuerdo de París; y escenario de emisiones altas con incremento de temperatura a final de siglo superior a 3 으 (RCP 8.5). Para el conjunto de la economía europea, incluida la actividad turística, el impacto del cambio climático, supondrá la pérdida anual del 1,5\% del PIB europeo, para el horizonte 20712100, para un incremento de temperatura de 20 C, valor de referencia del Acuerdo de París (2016), que rebasaría el $4 \%$ de pérdida anual en el PIB en escenarios de calentamiento elevado (RCP 8.5). Este efecto sería más notable en las regiones meridionales de Centro Europa y, 
especialmente, en los países el sur de Europa, por las consecuencias en los sectores agrario, sanitario y turístico.

En España, no son aún abundantes los ejemplos de adaptación al cambio climático en la escala local y, aun menos, en municipios turísticos de escala media o pequeña (Olcina y Vera, 2016a). Por lo general, las actuaciones orientadas a la lucha contra el cambio climático se han orientado, sobre todo, a las cuestiones energéticas, dejando al margen el desarrollo de medidas de tipo económico y territorial.

A efectos de planificación y adaptación de los espacios turísticos del litoral mediterráneo a las consecuencias del cambio climático, estos datos de proyección futura de variables atmosféricas, índices de confort y de temperatura del agua del mar Mediterráneo frente al litoral español va a suponer modificaciones para la planificación y gestión de los destinos turísticos. La Comunidad Valenciana no es ajena a estos cambios que suponen la necesidad de abordar la adaptación a los escenarios de modelización climática, como los analizados en el presente trabajo.

Figura 10. Efectos del cambio climático en la actividad turística y propuestas de actuación

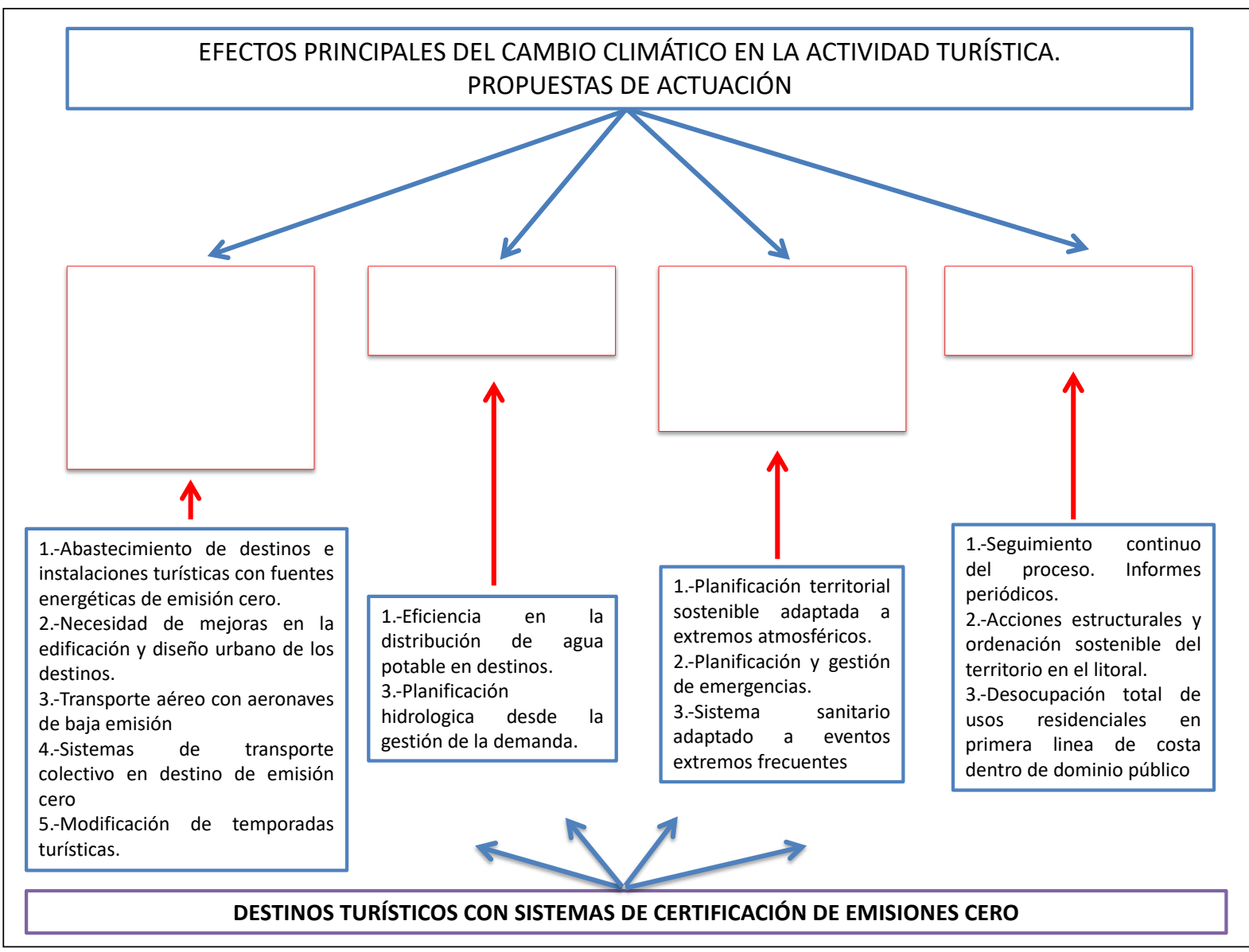

Elaboración propia. 
En síntesis, las actuaciones principales que deberá abordar la actividad turística de la Comunidad Valencina, especialmente en la modalidad de "sol y playa" ante la pérdida de confort climático y el incremento en los episodios atmosféricos extremos son las siguientes (Figura 10):

- La posibilidad de modificar el calendario de "temporada alta", muy centrada en la actualidad en julio y sobre todo agosto, que podrá prolongarse desde junio a septiembre, incluidos, además de considerar la estación primaveral junto con octubre muy aptos para las estancias turísticas en este espacio geográfico. Junto a ello, ganarían interés actividades turísticas en áreas montañosas de mayor altitud en la provincia.

- La necesidad de acondicionamiento climático de los establecimientos turísticos, de las viviendas residenciales y de las tramas urbanas a una situación más habitual de altas temperaturas y elevada humedad, diurna y nocturna, a los efectos de compensar el disconfort térmico que se estima creciente en los espacios costeros, especialmente a partir de mediados del siglo actual.

- La obligación de tener bien diseñados los sistemas de abastecimiento de agua, a escala regional y local, en un área con natural escasez de recursos, donde la propia reducción de precipitaciones, el aumento de la irregularidad en su desarrollo y el incremento de la evaporación en embalses, originará una disminución de volúmenes de agua superficial disponible.

- La necesidad, asimismo, de modicar, en la escala local, los protocolos de protección civil y sanidad pública, puesto que se van a alterar los calendarios de riesgo frente a determinados peligros de causa climática (tormentas y lluvias intensas por una mayor persistencia e intensidad de aguas cálidas en el Mediterráneo occidental a lo largo del año), así como la frecuencia e intensidad de aparición de extremos atmosféricos (olas de calor y sus efectos en grupos de riesgo). En esta cuestión será necesario mejorar los sistemas de drenaje de precipitaciones intensas en las ciudades turísticas en aras a la reducción de sectores de riesgo de anegamiento e inundación.

\section{CONCLUSIONES}

Los efectos del cambio climático en los elementos atmosféricos del litoral mediterráneo español ya son patentes. Se han registrado cambios en los patrones estacionales de las lluvias y en la intensidad de las mismas, cuestiones importantes para la planificación hidráulica y de las actividades económicas, especialmente la agraria. Pero son los cambios en la temperatura los que más inciden en el confort climático que es un recurso principal para el turismo. En este sentido, el presente trabajo muestra las alteraciones ya registradas en las temperaturas máximas y mínimas de la Comunidad Valenciana y su efecto en el índice de Confort Climático de Mieczkowski, así como la proyección del TCI para el presente siglo. En esencia los resultados del presente estudio señalan:

- El incremento de temperaturas máximas tórridas en verano, cuyo periodo de aparición tiende a expandirse hacia la segunda mitad de primavera, especialmente en Junio (Miró et al., 2015). 
- La frecuencia de noches tropicales está aumentando con fuerza en toda la franja litoral y prelitoral de la Comunitat (Olcina et al., 2019).

- La acusada pérdida de confort térmico del verano en la proyección hacia 2100 , lo que puede asociarse a unas temperaturas por encima del nivel óptimo de confort térmico, bien sea por máximas excesivas (preferentemente en el interior) o bien por la frecuencia de noches tropicales (preferentemente en el litoral).

La actividad turística es especialmente vulnerable al cambio climático. Algunas de sus modalidades (turismo de sol y playa; turismo de nieve) pueden ver alteradas sus actuales condiciones de competitividad en determinadas regiones turísticas mundiales. Sin caer en posturas extremas, algunos productos turísticos se verán modificados debido al cambio en las condiciones originales de los recursos ambientales. Las tres "exigencias" del turista en materia climática -disfrute, confort y seguridad-, que señalara Besancenot (1991), van a verse alteradas en las próximas décadas en los destinos turísticos mundiales; es posible ya proponer unas "nuevas exigencias" de obligada observancia en destinos expuestos al cambio climático (Tabla 3). Aunque la hipótesis de cambio climático por efecto invernadero de causa antrópica se sigue analizando por parte del IPCC en sus informes periódicos de cambio climático, sí se puede afirmar que el comportamiento de los elementos climáticos en algunas regiones del mundo se presenta como indicios de alteraciones no conocidas con anterioridad. Y ello supone cambios en las condiciones existentes hasta hace tres o cuatro décadas.

Tabla 3. Nuevas "exigencias" del turista en destinos expuestos al cambio climático

\begin{tabular}{|c|c|}
\hline ELEMENTO & EXIGENCIAS \\
\hline Transporte aéreo & - Aeronaves menos contaminantes (biocombustibles) \\
\hline Transporte en destino & $\begin{array}{l}\text { - Apuesta por movilidad sostenible en destinos (transporte } \\
\text { colectivo) } \\
\text { - } \text { Flotas de coches de alquiler eléctricos }\end{array}$ \\
\hline $\begin{array}{l}\text { Instalaciones hoteleras o de } \\
\text { apartamentos }\end{array}$ & $\begin{array}{l}\text { - Diseño ecológico de edificios } \\
\text { - Dispositivos y medidas de ahorro de energía y agua } \\
\text { - Implantación de tasas turísticas finalistas para adaptación } \\
\text { al cambio climático } \\
\text { - } \\
\text { Auditorías ambientales, con inclusión de parámetros de } \\
\text { adaptación al cambio climático }\end{array}$ \\
\hline Urbanismo & $\begin{array}{l}\text { - Diseño urbano sostenible y adaptado a la nueva realidad } \\
\text { climática en cada territorio } \\
\text { - Gestión inteligente de destinos } \\
\text { - Indicadores de capacidad de carga } \\
\text { - Adaptación de tramas urbanas a extremos climáticos }\end{array}$ \\
\hline
\end{tabular}

Elaboración propia.

La rapidez de adaptación que manifiesten las actividades económicas expuestas a las condiciones ambientales (agricultura y turismo, principalmente) permitirá mantener, en mayor o menor medida, su competitividad en las economías regionales y su protagonismo en los 
territorios expuestos al cambio climático. Otra cuestión es que los gobiernos vayan apostando por modelos económicos más racionales y circulares, donde no se persiga el crecimiento ilimitado como objetivo prioritario a cubrir anualmente; comportamiento común de las economías neoliberales, que se ha demostrado insostenible e insolidario social y económicamente. Y el turismo ha contribuido a afianzar dicho modelo causando, además, efectos en el medio y su atmósfera que van a ser difíciles de superar.

\section{AGRADECIMIENTOS}

Este trabajo ha sido posible realizarlo gracias al Ministerio de Economía y Competitividad de España y al Fondo Europeo de Desarrollo Regional (FEDER) a través del proyecto CLIMTEX CGL2015-64268-R (MINECO/FEDER, UE).

\section{REFERENCIAS BIBLIOGRÁFICAS}

Aemet (2015). Generación de escenarios regionalizados de cambio climático en España. Disponible en http://www.aemet.es/documentos/es/elclima/cambio climat/escenarios/Informe Escenarios.pdf. (Consultado en noviembre 2019).

Amelung, B.; Nicholls, S.; Viner, D. (2007). Implications of global climate change for tourist flows and seasonality. Journal of Travel Research, 45, pp. 285-296.

Anton Clavé, S.; Rullan Salamanca, O.; Vera Rebollo, J.F. (2011). Mass Tourism Development on the Mediterranean Coast. Tourism Geographies, 13:3, 495-501.

Argüeso, D. (2011). High-resolution projections of climate change over the Iberian Peninsula using a mesoscale model. Ph. D. Thesis. Departamento de Física Aplicada. Universidad de Granada.

Barros Pozo, P.M. y Martín Vide, J. (2018). Influencia térmica antrópica local y global en el observatorio Fabra para el periodo 1924-2016. Boletín de la Asociación de Geógrafos Españoles, 79, 1-23.

Beck, U. (2002). La sociedad del riesgo global, Madrid: Siglo XXI.

Besancenot, J. P. (1991). Clima y Turismo. Ed. Masson. Barcelona, 224 p.

Bigano, A. Hamilton, J.M. and Tol, R.S.J. (2008). Climate change and tourism in the Mediterranean. Working Paper FNU-157. Research Unit Sustainable and Global Change. Hamburg University. Disponible en http://www.fnu.zmaw.de/HTM.5681.0.html. (Consultado en octubre 2019).

Blasco Laffón, B.; E. Blasco Laffón, E.; J. M. Fernández Valdés, J.M.; Viñas Arrebola, C. (2007). Cálculo de índices de confort térmico en recintos cerrados con transferencia de calor. En I Jornada Nacional de Investigación en edificación. Madrid.

Brunet, M., Casado, M.J., De-Castro, M., Galán, P., López, J.A., Martín, J.M., Pastor, A., Petisco, E., Ramos, P., Ribalaygua, J., Rodríguez, E., Sanz, I. y Torres, L. (2009). Generación de escenarios climáticos regionalizados para España. Agencia Estatal de Meteorología. Madrid, $157 \mathrm{p}$.

Bujosa, A. y Rosello, J. (2011). Cambio climático y estacionalidad turística en España: un análisis del turismo doméstico de costa. Estudios de Economía Aplicada, 29(3), 863-880. 
Carreras, C.; Marín, M.; Martín Vide, J.; Moreno, Ma C. y Sabi, J. (1990). Modificaciones térmicas en las ciudades. Avance sobre la isla de calor en Barcelona. Documents d'Analisi Geográfica. 17, 51-77.

De Luis, M.; Brunetti, M.; Gonzalez-Hidalgo, J.C.; Longares, L.A.; Martin-Vide, J. (2010). Changes in seasonal precipitation in the Iberian Peninsula during 1946-2005. Global and Planetary Change, 74 (1), pp. 27-33.

Del-Río, S., Cano-Ortiz, A., Herrero, L., Penas, A. (2012). Recent trends in mean maximum and minimum air temperatures over Spain (1921-2006). Theoretical and Applied Climatology, 109, 605-626, doi: 10.1007/s00704-012-0593-2.

Dubois AND Ceron, (2006). Tourism and climate change: Proposals for a research agenda. Journal of Sustainable Tourism, 14 (4): 399-415.

El Kenawy, A., López-Moreno, J.I. y Vicente-Serrano, S.M. (2012). Trend and variability of surface air temperature in northeastern Spain (1920-2006): Linkage to atmospheric circulation. Atmospheric Research, 106: 159-180, doi:10.1016/j.atmosres.2011.12.006

ESPON Climate. (2011). Climate Change and Territorial Effects on Regions and Local Economies. Main Report. Disponible en: https://www.espon.eu/climate. (Consultado en noviembre 2019).

Fernández García, F. (1994). Clima y confortabilidad humana. Aspectos metodológicos. Serie Geográfica, vol. 4, 109-125.

Gómez Royuela, M. (2016). Impactos, vulnerabilidad y adaptación al cambio climático en el sector turístico. Madrid. Oficina Española de Cambio Climático. Ministerio de Agricultura, Alimentación y Medio Ambiente, 82 p.

Gössling, S., Peeters, P. y Scott, D. (2008). Consequences of Climate Policy for International Tourist Arrivals in Developing Countries. Third World Quarterly, 29(5), 873-901.

Greenpeace España y Observatorio De La Sostenibilidad (2018). A toda costa. Análisis de la evolución y estado de conservación de los bienes y servicios que proporcionan las costas. Disponible en: https://es.greenpeace.org/es/sala-de-prensa/informes/a-todacosta/ (Consultado en marzo 2020).

Hamilton, L.C. y B.D. Keimb, (2009). Regional variation in perceptions about climate change. International Journal of Climatology, 29, pp. 2348-2352.

INE (2019). Cuenta satélite del Turismo en España, 2019. Madrid. Disponible en: https://www. ine.es/dyngs/INEbase/es/operacion.htm?c=Estadistica C\&cid=1254736169169\&menu=ultiDatos\&idp=1254735576863. (Consultado en marzo 2020).

IPCC (Intergovernmental Panel on Climate Change) (2014). Climate Change 2013 and Climate Change 2014 (3 vols.). Disponible en: http://www.ipcc.ch/

IPCC (Intergovernmental Panel on Climate Change) (2018). Global Warning of 1,5o C. Special Report. Disponible en: https://www.ipcc.ch/sr15/

JRC (2014). Climate Impacts in Europe. The JRC PESETA /I Project. Luxembourg, Publications Office of the European Union, 155 p. Disponible en: https://publications.jrc.ec.europa. eu/repository/handle/JRC87011. (Consultado en octubre 2019)

JRC (2018). Climate Impacts in Europe. Final report of the JRC PESETA III project. 90 p. Disponible en: https://ec.europa.eu/irc/en/peseta-iii (Consultado en octubre 2019).

Lenzen, M., Sun, Y., Faturay, F., Ting, Y.P, Geschke, A y Malik A. (2018). The carbon footprint of global tourism. Nature Climate Change 8, 522-528. 
López Palomeque, F. Marchena Gómez, M., Antón Clavé, S. y Vera Rebollo, J.F. (2011). Análisis territorial del turismo y planificación de destinos turísticos. Valencia. Ed. Tirant lo Blanch, $472 \mathrm{p}$.

Martín-Vide, J.; Sarricolea, P. y Moreno-García, M.C. (2015). On the definition of urban hear island intensity: the "rural" reference. Frontiers in Earth Science, 34: 24.

Mieczkowski, Z.T. (1985). The tourism climatic index: a method of evaluating world climates for tourism. The Canadian geographer, n-29, p. 220-33.

Millán López, A. y Fernández García, F. (2018). Propuesta de un índice climático-turístico adaptado al turismo de interior en la Península Ibérica: aplicación a la ciudad de Madrid. Investigaciones Geográficas, 70, 31-46. https://doi.org/10.14198/INGEO2018.70.02

Ministerio De Medio Ambiente, Medio Rural y Marino (2007). Programa A.G.U.A. (Actuaciones para la Gestión y la Utilización del Agua). Madrid, 45 pp.

Miró, J.J., Estrela, M.J. y Millán, M. (2006). Summer temperature trends in a mediterranean area (Valencia region). International Journal of Climatology, no 26, p. 1051-1073, doi: 10.1002/joc.1297.

Miró, J.J. (2014). Downscaling estadístico de series climáticas mediante redes neuronales: Reconstrucción en alta resolución de la temperatura diaria para la Comunidad Valenciana. Interpolación espacial y análisis de tendencias (1948-2011). Tesis Doctoral. Universidad de Alicante, Fundación Centro de Estudios Ambientales del Mediterráneo, y Universidad de Valencia. 523p., doi: 10.13140/ RG.2.1.2059.1523

Miró, J.J., Estrela, M.J. y Olcina, J. (2015). Statistical downscaling and attribution of air temperature change patterns in the Valencia region (1948-2011). Atmospheric Research, 156: 189-212, doi:10.1016/j.atmosres.2015.01.003

Miró, J.J., Estrela, M.J. y Olcina, J. (2016a). Reconstrucción de la señal térmica local en la Comunidad Valenciana entre 1948 y 2011 a partir de un downscaling estadístico mediante una red neuronal artificial: Detección de patrones locales de cambio. Boletín de la Asociación de Geógrafos Españoles, 70, 113-147 (eng:471- 475), doi:10.21138/ bage. 2165

Miró, J.J., Estrela, M.J., Caselles, V. y Olcina, J. (2016b). Fine-scale estimations of bioclimatic change in the Valencia region, Spain. Atmospheric Research, 180: 150-164, doi:10.1016/j.atmosres.2016.05.020

Miró Pérez, J.; Olcina Cantos, J. Estrela Navarro, M.J. y Caselles Miralles, V. (2016c). Confor climático, cambio climático y actividad turística en Alicante. X Congreso Internacional AEC: Clima, sociedad, riesgos y ordenación del territorio. Publicaciones AEC. DOI: $\underline{\text { http:// }}$ dx.doi.org/10.14198/XCongresoAECAlicante2016-63

Miró, J.J., Caselles, V. y Estrela, M.J. (2017). Multiple imputation of rainfall missing data in the Iberian Mediterranean context. Atmospheric Research, 197: 313-330. DOI: http:// dx.doi.org/10.1016/j.atmosres.2017.07.016

Miró J.J., Estrela M.J., Caselles V., Gómez I. (2018). Spatial and temporal rainfall changes in the Júcar and Segura basins (1955-2016): finescale trends. International Journal of Climatology, 2018: 4699-4722.

Morata, A. (2014). Guía de escenarios regionalizados de cambio climático sobre España a partir de los resultados del IPCC-AR4. Nota técnica AEMET. 197p. 
Moreno García, M.C. (1993). Estudio del clima urbano de Barcelona. La isla de calor. Universidad de Barcelona, Barcelona.

Moreno García, M.C y Serra Pardo, J.A. (2016). El estudio de la isla de calor urbana en el ámbito mediterráneo: una revisión bibliográfica. Biblio 3W: Revista Bibliográfica de Geografía y Ciencias Sociales, vol. 21.

Olcina, J. y Vera-Rebollo, J.F. (2016a). Adaptación del sector turístico al cambio climático en España. La importancia de las acciones a escala local y en empresas turísticas. Anales de Geografía de la Universidad Complutense, 36 (2), 331-349.

Olcina, J. y Vera-Rebollo, J.F. (2016b). Climate change and tourism policy in Spain: Diagnosis in the Spanish mediterranean coast. Cuadernos de Turismo de la Universidad de Murcia, 38, 565-571.

Olcina, J., Baños, C. y Rico, A. M. (2016c). Medidas de adaptación al riesgo de sequía en el sector hotelero de Benidorm (Alicante, España). Revista de Geografía Norte Grande, no 65, 129-153.

Olcina Cantos, J. y Miró Pérez J.J. (2016d). El clima, recurso básico del turismo alicantino. De la valoración del clima invernal al aprovechamiento intensivo del clima estival. Revista Canelobre, 65 (monografico sobre la actividad turística en la provincia de Alicante). Diputación Provincial de Alicante, 3-21.

Olcina, J. (2017). Incremento de episodios de inundación por lluvias de intensidad horaria en el sector central del litoral mediterráneo español: análisis de tendencias en Alicante. Revista Semata, 29, 143-163.

Olcina, J. y Miró, J. (2017). Actividad turística y cambio climático en la Comunidad Valenciana. Alicante: Universidad de Alicante, Instituto Universitario de Investigaciones Turísticas; Valencia: Agència Valenciana del Turisme. doi:10.14198/201. Disponible en: http:// dx.doi.org/10.14198/2017-Actividad-Turistica-ComValenciana.

Olcina, J., Serrano-Notivoli, R., Miró. J. y Meseguer-Ruiz, O. (2019). Tropical nights on the Spanish Mediterranean coast, 1950-2014. Climate Research, 78 (3): 225-236.

Pastor, F., Valiente, J.A. y Estrela, M.J. (2015). Sea surface temperature and torrential rains in the Valencia region: modelling the role of recharge areas. Natural Hazards and Earth System Sciences, 15: 1677-1693, doi:10.5194/ nhess-15-1677-2015.

Pastor, F., Valiente, J.A. y PALAU, J.L. (2018). Sea Surface Temperature in the Mediterranean: Trends and Spatial Patterns (1982-2016), Pure and Applied Geophysics, 175: 4017-4029. https://doi.org/10.1007/s00024-017-1739-z

Pulido-Fernández, J.I. y López-Sánchez, Y. (2014). Turismo y Cambio Climático. Propuesta de un Marco Estratégico de Acción. Revista de Economía Mundial, 36, 257-283.

Rico Amorós, A., Olcina Cantos, J. y Saurí, D. (2009). Tourist Land Use Patterns and Water Demand. Evidence from the Western Mediterranean. Land Use Policy, 26, 493-501.

Rico, A., Saurí, D., Olcina Cantos, J. y Vera Rebollo, J.F. (2013). Beyond Megaprojects?. Water Alternatives for mass tourism in Coastal Mediterranean Spain. Water Resources Management. Nov. 2012. DOI: 10.1007/s11269-012-0201-3

Roselló, J. (2011). España, Turismo y cambio climático. Economistas, 127, 28-34.

Royé, D. y Martí Ezpeleta, A. (2015). Análisis de las noches tropicales en la fachada atlántica de la península ibérica. Una propuesta metodológica. BAGE, 69, 351-368. 
Royé, D. (2017). The effects of hot nights on mortality in Barcelona, Spain. International Journal of Biometeorology, 61: 2127-2140. https://doi.org/10.1007/s00484-017-1416-z

Salvati, A., Roura, H. C., y Cecere, C. (2017). Assessing the urban heat island and its energy impact on residential buildings in Mediterranean climate: Barcelona case study. Energy and Buildings, 146, 38-54.

Saurí, D., Olcina, J., March, H., Martín-Vide, J., Vera, F., Padilla, E. y Serra-Llobet, A. (2011). Case Study Mediterranean Coast of Spain. En ESPON Climate: Climate Change and Territorial Effects on Regions and Local Economies. Applied research project 2012/1/4. Final Report. Annex 4. Disponible en: https://www.espon.eu/sites/default/files/attachments/Final\%20Report\%20Main\%20Report.pdf. (Consultado en noviembre 2019).

Sánchez-Lorenzo, A., Pereira, P., López-Bustins, J.A. y Lolis, C.J. (2011). Summer night-time temperature trends on the Iberian Peninsula and their connection with large-scale atmospheric circulation patterns. International Journal of Climatology, 32(9):13261335. https://doi.org/10.1002/joc.2354

Scott, D. (2008). Climate Change and Tourism: Responding to Global Challenges. Conferencia pronunciada en el marco del CTO/CRSTDP Regional Workshop. The Bahamas, 18-19 March 2008. Disponible en http://www.onecaribbean.org/content/files/ DavosReportOverviewDanScott.pdf. (Consultado en junio 2018).

Scott, D., Hall, C.M., y Gössling, S. (2011). Climate change and tourism: Impacts, adaptation and mitigation. London, Routledge.

Stern, N. (2006). The Economics of Climate Change: The Stern Review. Cambridge: Cambridge University Press.

Tuan, Y.F. (2018). El arte de la geografía. Icaria: Barcelona.

UNWTO (2017). Tourism and the Sustainable Development Goals - Journey to 2030, Highlights. UNWTO: Madrid. Disponible en: https://www.e-unwto.org/doi/ pdf/10.18111/9789284419340. (Consultado en enero 2020)

UNWTO (2019). Panorama OMT del turismo internacional, edición 2019. Madrid: Organización Muncial del Turismo. Disponible en: https://www.e-unwto.org/doi/ pdf/10.18111/9789284421237 (Consultado en enero 2020)

UNWTO y UNEP (2008). Climate change and tourism. Responding to global challenges. Madrid: UNWTO.

Vardoulakis, E., Karamanis, D., Fotiadi, A. y Mihalakakou, G. (2013). The urban heat island effect in a small Mediterranean city of high summer temperatures and cooling energy demands. Solar energy, 94, 128-144.

Vera Rebollo, J. F. (1985). Las condiciones climáticas y marítimas como factores de localización del turismo histórico alicantino. Investigaciones Geográficas no 3, 161-178.

Vera Rebollo, J.F. (1987). Turismo y urbanización en el litoral alicantino. Instituto de estudios Juan Gil Albert, Diputación Provincial de Alicante.

Vera Rebollo, J.F. y Baños, C.J. (2010). Renovación y reestructuración de los destinos turísticos consolidados del litoral: las prácticas recreativas en la evolución del espacio turístico. Boletín de la Asociación de Geógrafos Españoles, 53: 329-353.

Vera Rebollo, J.F. y Rodriguez Sánchez, I. (Eds.) (2012). Renovación y reestructuración de destinos turísticos en áreas costeras, Publicaciones de la Universitat de València, 429 p. 
WTTC (2019). El turismo crecerá por encima de la media europea. eTurbo news. Disponible en: https://www.tourinews.es/resumen-de-prensa/notas-de-prensa-espana-turismo/ wttc-el-turismo-en-espana-crecera-por-encima-de-la-media-europea_4453400 102. html. (Consultado en marzo 2020). 